PACS 81.40.--Z

\title{
Effect of deformation temperature on grain refinement in alpha titanium alloy VT5-1
}

\author{
M.A. Murzinova \\ mma@imsp.ru \\ Institute for Metals Superplasticity Problems RAS, 39 Khalturin St., 450001 Ufa, Russia
}

\begin{abstract}
Alpha titanium alloys exhibit good thermal stability, corrosion resistance, satisfactory toughness, but these alloys cannot be strengthened by heat treatment. One of the ways of their strengthening is to produce fine-grained microstructure during deformation. Grain size in materials subjected to hot and warm deformation depends on flow stresses, which significantly vary with conditions of deformation. In the article, the data on flow stresses and microstructural parameters of alpha titanium alloy VT5-1 (Ti-5Al-2.5Sn) subjected to isothermal deformation at temperatures varying from 940 to $650^{\circ} \mathrm{C}$ are represented. Technique of electron backscattering diffraction was applied for quantitative analysis of the microstructure. Obtained results were used to define the relationships between i) flow stress and the mean grain size in deformed alloy, ii) temperature of deformation and mean sizes of grain and subgrain, iii) temperature of deformation and tensor dislocation density. It was shown that discontinuous dynamic recrystallization prevailed in the VT5-1 alloy at deformation temperatures higher than $\sim 840^{\circ} \mathrm{C}$ and continuous dynamic recrystallization prevailed at $650-840^{\circ} \mathrm{C}$. Decrease in the deformation temperature from 940 to $650^{\circ} \mathrm{C}$ led to tenfold decrease in the size of dynamically recrystallized grains. Microstructure with the mean grain size of 0.7 micrometers and high dislocation density was obtained after deformation at $650^{\circ} \mathrm{C}$. Formation of the fine-grained structure resulted in an increase Brinell hardness of the alloy by almost 1.4 times in comparison with the initial coarse-grained condition.
\end{abstract}

Keywords: alpha titanium alloy, dynamic recrystallization.

\section{Introduction}

Merits of alpha titanium alloys are good thermal stability, corrosion resistance, satisfactory toughness, but these alloys cannot be strengthened by heat treatment [1-3]. One of the ways of their strengthening is to produce finegrained microstructure during deformation. Conditions and mechanisms of microstructure refinement were studied in details for commercial pure titanium in wide interval of deformation temperatures [4,5], whereas similar investigations for alloyed alpha titanium alloys are very limited because of poor workability of the alloys with substitutional alloying elements at temperatures below 700$800^{\circ} \mathrm{C}$.

The purpose of the present work is to study the effect of deformation temperature on structure development of the alpha titanium alloy VT5-1 during isothermal deformation at $940-650^{\circ} \mathrm{C}$.

\section{Materials and experimental techniques}

Hot-deformed slab of the VT5-1 alloy with the chemical composition of Ti-5.4Al-2.8Sn (wt. \%) and the content of impurities less than 0.25 wt. \% was used as a starting material. The alloy had a coarse-grained lamellar-type microstructure. The size of $\alpha$-colonies was $300-500 \mu \mathrm{m}$ and the thickness of a-lamellae was within 5-15 $\mu \mathrm{m}$.
Cylindrical samples with $10 \mathrm{~mm}$ in diameter and $15 \mathrm{~mm}$ in height were cut from the slab and compressed isothermally at temperatures varying from 940 to $650^{\circ} \mathrm{C}$. To decrease friction between the surfaces of the dies and the specimen, boron nitride grease was used. Soaking of the samples prior to deformation was $20 \mathrm{~min}$. Compression tests were performed using a Schenk mechanical testing system at a constant crosshead speed of $0.27 \mathrm{~mm} / \mathrm{min}$ to the height reduction of $60 \%$. To prevent post-deformation structure development each specimen was immediately water-cooled after test. The results of compression tests were used for plotting the true stress-strain curves.

Microstructure of the deformed samples was examined in their cross sections by transmission electron microscopy (TEM) and electron backscatter diffraction (EBSD) techniques. EBSD analysis was conducted using Mira 3 Tescan scanning electron microscope equipped with Oxford Instruments HKL Channel 5 software.

Grain-boundary misorientations below $2^{\circ}$ were excluded from the data analysis [6]. A boundary misorientation of $15^{\circ}$ was used to define low-angle and high-angle boundaries. The values of equivalent diameter of grain and subgrain were taken as a characteristic of grain and subgrain sizes. Details of the quantitative microstructure analysis were described in [7]. Data of misorientation angle inside of each grain were taken to calculate tensor density of dislocations as it was suggested in [8]. 


\section{Results and discussion}

Fig.1 presents true stress-strain curves plotted from compression tests data. The curves exhibited an initial hardening transient, flow softening at high deformation temperatures and steady-state flow stage $\left(\sigma_{\mathrm{ss}}\right)$. Such type of curves is typical for hot and warm deformations at which dynamic recovery and recrystallization take place [9-12].

During isothermal deformation at temperatures from 940 to $650^{\circ} \mathrm{C}$, the initial lamellar microstructure of the VT51 alloy was transformed to fine-grained one. Deformation at temperatures lower than $650^{\circ} \mathrm{C}$ gave rise to cracks appearance on the side surface of the samples after the height reduction by $20-40 \%$. Typical maps of microstructure of the samples deformed at high and low temperatures are shown in Figures 2a,b. Deformation-induced low angle boundaries and dislocations were observed inside the grains in all cases that was confirmed by TEM observations (Fig.2c,d). It is evident that dynamic recovery and dynamic recrystallization (DRX) took place during deformation of the VT5-1 alloy.

The mean size of grains/subgrains (D/d), which were formed in the alloy during deformation, obeys a powerlaw of the steady-state flow stress [9-12]. The empirical relationship can be expressed as $\sigma_{\mathrm{s}} / \mu \propto D^{-N}$, where $\mu$ is temperature dependent shear modulus of the alloy and $N$ is the grain size exponent [10-12]. Relationship between the mean size of $\alpha$-grains/subgrains and the steady-state flow stress normalized by shear modulus for VT5-1 alloy is given in Figure $3 \mathrm{a}$ (the value of shear modulus at room temperature was taken from Ref. [13] and those for higher temperatures
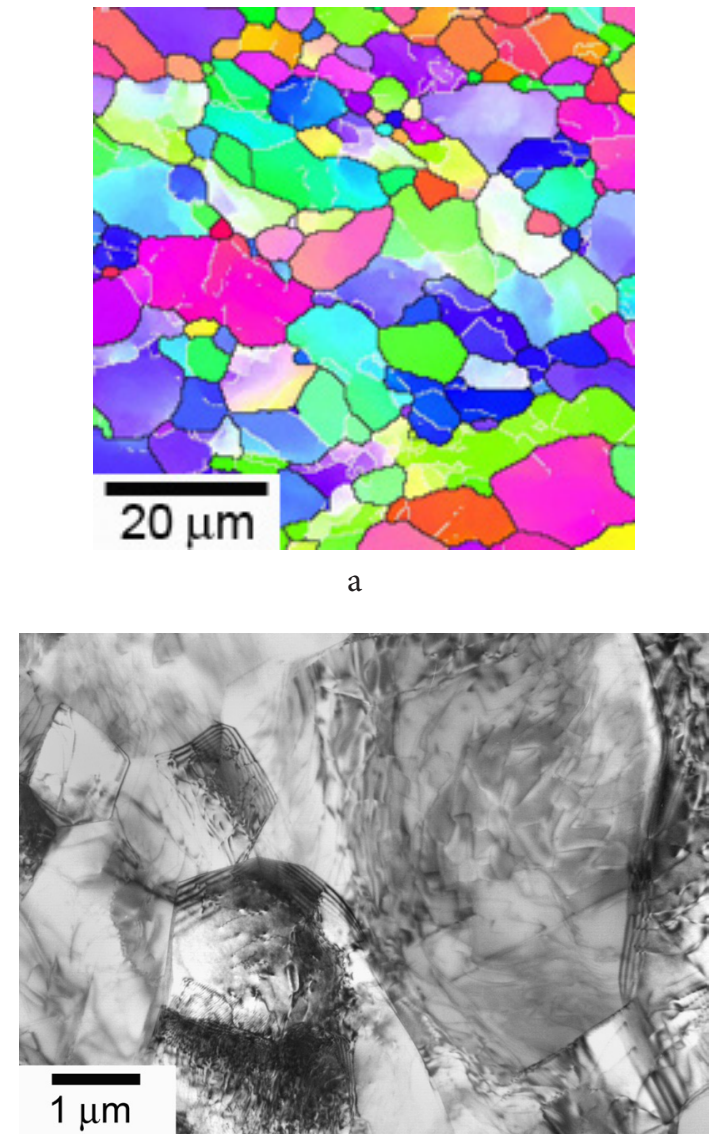

C were calculated according [14]). The relationship $D-\sigma_{\mathrm{ss}} / \mu$ consisted of two lineal parts. The value of $N$ ( $N$ shows inclination of the lineal part of the function) was 0.93 for the part corresponding to lower stresses and coarser grains that is typical for discontinuous dynamic recrystallization $[4,5,9-$ $12,15,16]$. The value of $N$ for the lineal part corresponding to higher stresses and smaller grains was 0.31 indicating continuous dynamic recrystallization $[4,5,15,16]$. Change of the main mechanism of DRX took place at deformation temperature of $\sim 840^{\circ} \mathrm{C}$ and stress level of $\sim 7.5 \times 10^{-3} \mu$. This result is similar to commercial pure titanium $[4,5]$, but the transition from discontinuous to continuous DRX occurs at temperature by $\sim 200$ degrees higher than in titanium.

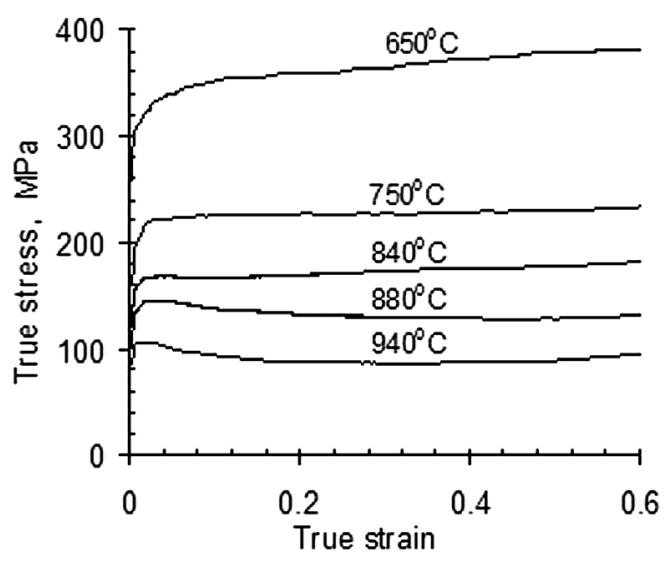

Fig. 1. True stress-strain curves of VT5-1 alloy compressed at different temperatures.

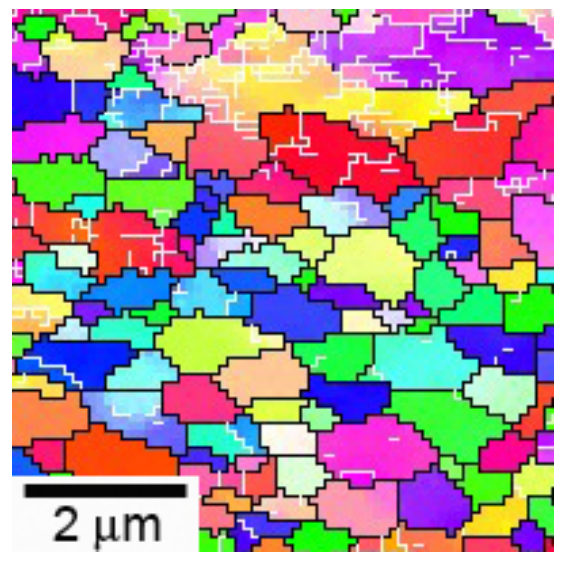

$\mathrm{b}$

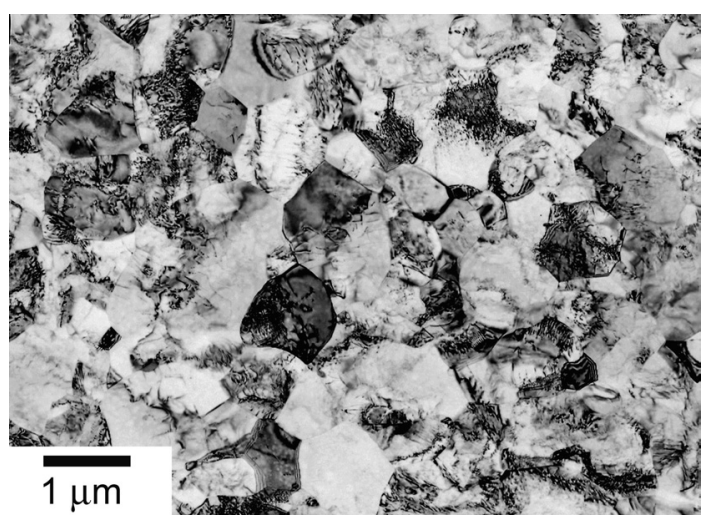

$\mathrm{d}$

Fig. 2. Microstructure maps (a,b) and TEM images (c,d) of VT5-1 alloy deformed at $880^{\circ} \mathrm{C}(\mathrm{a}, \mathrm{c})$, and $650^{\circ} \mathrm{C}(\mathrm{b}, \mathrm{d})$. 


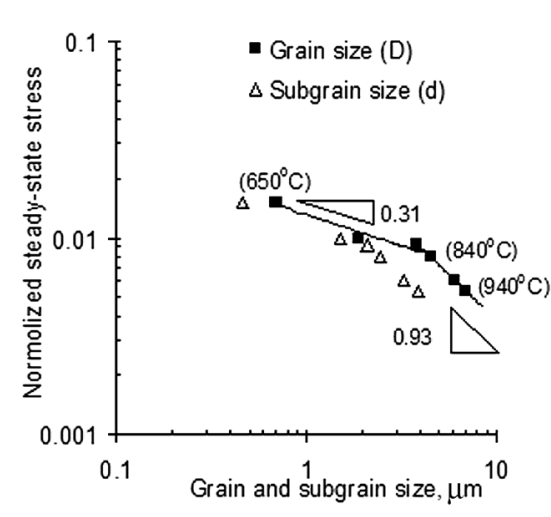

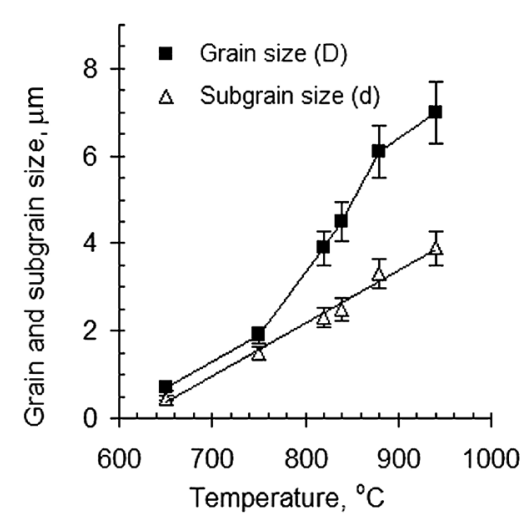

$\mathrm{b}$

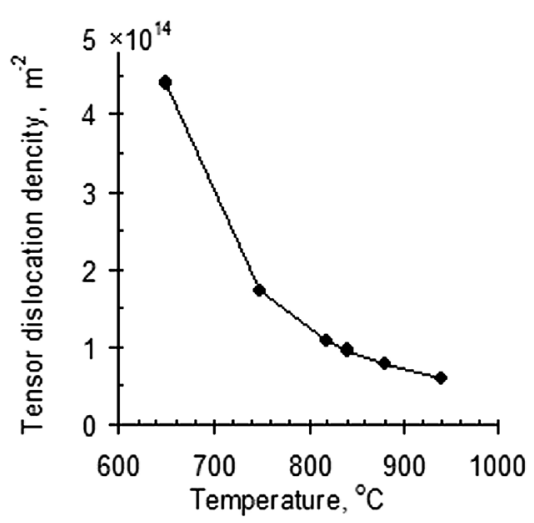

Fig. 3. The normalized steady-state flow stress vs. recrystallized $\alpha$-grain/subgrain size in VT5-1 alloy (corresponding temperatures of deformation are given in parenthesis) (a), effect of deformation temperature on the mean size of grains/subgrains (b), and tensor dislocation density (c) in VT5-1 alloy.

Temperature dependences of the mean grain/subgrain sizes and the tensor dislocation density are shown in Figure $3 b, c$. The mean grain size reduces and tensor dislocation density increased by an order of magnitude with decreasing the temperature of deformation from 940 to $650^{\circ} \mathrm{C}$. An inflection in the temperature dependence of grain size was observed at $\sim 840^{\circ} \mathrm{C}$. The mean subgrain size was approximately two times smaller than the mean grain size after deformation at $940-840^{\circ} \mathrm{C}$, and those sizes became closer after deformation at $750-650^{\circ} \mathrm{C}$. Essential difference in grain and subgrain sizes is typical for discontinuous DRX [5,9-12,15-17], whereas the small difference in these sizes and higher dislocation density indicates the occurrence of continuous DRX at which migration of high-angle boundaries is impeded [5,15-18].

Formation of fine-grained microstructure with high dislocation density gave rise to strengthening of the VT5-1 alloy. The Brinell hardness of the alloy with coarse-grained lamellar microstructure was $240 \mathrm{MPa}$ and increased up to $330 \mathrm{MPa}$ in the alloy with mean grain size $0.7 \mu \mathrm{m}$ obtained after deformation at $650^{\circ} \mathrm{C}$.

\section{Conclusions}

Flow stresses and microstructural parameters of alpha titanium alloy VT5-1 subjected to isothermal deformation at temperatures from 940 to $650^{\circ} \mathrm{C}$ were examined. It was found that:

i. Discontinuous dynamic recrystallization prevailed in the VT5-1 alloy at temperatures of deformation higher than $\sim 840^{\circ} \mathrm{C}$ while continuous dynamic recrystallization occurred at $650-840^{\circ} \mathrm{C}$.

ii. Decrease in the deformation temperature from 940 to $650^{\circ} \mathrm{C}$ led to decrease in the size of dynamically recrystallized grains from 7 to $0.7 \mu \mathrm{m}$.

iii. The Brinell hardness of the fine-grained VT5-1 alloy is $330 \mathrm{MPa}$ that is about 1.4 times higher as compared to the hardness of the coarse-grained lamellar material.

\section{References}

1. M. J. Donachie. Titanium: A Technical Guide, ASM International. (1988) p 28.

2. G. Lütjering, J.C. Williams, Titanium - Engineering Materials and Processes, 2nd edition, Springer-Verlag Berlin Heidelberg. (2007), 449 p.

3. D. Banerjee, J.C. Williams, Acta Mater. 61, 844 (2013).

4. S. V. Zherebtsov, G. A. Salishchev, R.M. Galeyev, Defect and Diffusion Forum, 208-209, 237 (2002).

5. A. Belyakov, S. Zherebtsov, G. Salishchev. Materials Science \& Engineering. A 628, 104 (2015).

6. F. J. Humphreys, J. Mater. Sci. 36, 3833 (2001).

7. M. A. Murzinova. Letters on materials. 4 (4), 214 (2014).

8. Q. Liu, D. J. Jensen, N. Hansen. Acta Mater. 46, 5819 (1998).

9. T. Sakai, J.J. Jonas, Acta Metall. 32, 189 (1984).

10. B. Derby Acta Metall. Mater. 39, 955 (1991).

11. F. J. Humphreys and M. Hatherly, Recrystallization and Related Annealing Phenomena, 2nd ed. Elsevier Ltd. 628 p. (2004).

12. H.J. McQueen, Metall. Sci, \& Technology, 28 (1), 12 (2010).

13. Materials in mechanical engineering. Vol. 1. Nonferrous metals and alloys. Ed. by I. V. Kudrayvcev, L. P. Luzhnikov. Handbook in 5 volumes. Moscow, Mashinostroenie (Mechanical engineering) (1967) 304 p. (in Russian).

14. H.J. Frost, M.F. Ashby. Deformation-mechanism maps. Oxford, Pergamon press. (1982).

15. A. Belyakov, T. Sakai, H. Miura, K. Tsuzaki, Philos. Mag. A, 81, 2629 (2001).

16. A. Belyakov, K. Tsuzaki, H. Miura, T. Sakai, Acta Mater. 51, 847 (2003).

17. O. S. Sitdikov. Letters on materials. 5 (1), 74 (2015) (in Russian).

18. O. Sitdikov, T. Sakai, E. Avtokratova, R. Kaibyshev, K. Tsuzaki, Y. Watanabe. Acta Mater. 56, 821 (2008). 